\title{
COVID-19: A New Coronavirus
}

\author{
José Luis Corona Lisboa ${ }^{1,2}$ \\ ${ }^{1}$ Nathional Experimental University Francisco of Miranda. Mene de Mauroa, Venezuela. \\ ${ }^{2}$ Research and Postgraduate Department, Panamerican Center for Higher Studies, Heroica Zitácuaro, México.
}

\begin{abstract}
How to cite this paper: José Luis Corona Lisboa. (2020) COVID-19: A New Coronavirus. International Journal of Clinical and Experimental Medicine Research, 4(2), 18-20.

DOI: $10.26855 /$ ijcemr.2020.04.003
\end{abstract}

Received: March 20, 2020

Accepted: April 15, 2020

Published: April 23, 2020

*Corresponding author: José Luis Corona Lisboa, Nathional Experimental University Francisco of Miranda. Mene de Mauroa, Venezuela; Research and Postgraduate Department, Panamerican Center for Higher Studies, Heroica Zitácuaro, México.

Email:

joseluiscoronalisboa@gmail.com

\begin{abstract}
Viruses are chemical particles of genetic material, where very virulent families and genera are found. The world is facing a new highly pathogenic coronavirus, the clinical picture of which changes dramatically depending on the immune status of the patient. The objective of this article was to capture the biological generalities and particularities of the new coronavirus (COVID-19). Likewise, the clinical manifestations of this virus and the prophylactic measures issued by the health agencies in charge of combating this pandemic are detailed.
\end{abstract}

\section{Keywords}

COVID-19, Coronavirus, Pandemic, China

\section{Introduction}

Since human history, pandemics have plagued the world in various episodes, leaving many deaths in its wake. Right now, we are facing one of them caused by a new Coronavirus called COVID-19, which is present in more than 130 countries worldwide.

The objective of this article is to capture the biological generalities and particularities of COVID-19. Likewise, the clinical manifestations of this virus and the prophylactic measures issued by the health agencies in charge of combating this pandemic are detailed.

\section{Materials and Methods}

This study was framed in the bibliographic design under the systematic review and of different collected and selected documents. The type of investigation corresponded to the documentary, with the inquiry into the information and data obtained in the different electronic repositories. The investigation contemplated logical and mental procedures of analysis, synthesis, deduction and induction [1].

\section{Results and Discussion}

Microorganisms were the first living beings that inhabited the planet earth, coming from oxygen and food through various biochemical processes, such as photosynthesis, cellular respiration, among others. Among these microbes, we can mention: bacteria, cyanobacteria, fungi, parasites and viruses. The latter appeared as apparently inert molecules, but then scientists discovered that they are endowed with several impressive reproductive 
mechanisms, to the point of parasitizing pathogenic bacteria of medical importance, such as E. coli and others [2].

With the discovery of viruses, a controversy arose that continues to this day: are viruses living beings? According to the basic characteristics of living beings, for an organism to be considered "living" as such, it must have its own mechanisms of cellular reproduction, and viruses can only reproduce if they are inside a host cell, otherwise they will not they are capable on their own [3].

Therefore, a virus is considered as a chemical molecule consisting essentially of genetic material, either Deoxyribonucleic Acid or Ribonucleic Acid, endowed with nucleotides with a specific genetic sequence for viruses, capable of entering the host cell genome, and taking over the genetic and metabolic machinery of the same, to produce the proteins that the virus needs to replicate. This wonder of natural genetic engineering, we can only observe and study in viruses, which despite not being considered alive, are magnificently impressive.

There are hundreds of serotypes belonging to viruses, of which many of them are highly pathogenic (virulent) causing deadly diseases such as HIV/AIDS, Hebola virus, among others. Likewise, scientific evidence has shown that viruses can mutate (changes in their genetic code) spontaneously or intentionally caused in a laboratory by man, with the use of UV, Gamma, Infrared, X, drugs, among others [4].

Viruses are very susceptible to changes in the natural environment and to controlled conditions in a laboratory. In this sense, the mutation capacity and virulence are significantly affected, making them resistant to drugs, climatic variables (temperature, humidity, etc.). What has been observed epidemiologically in Europe and the United States is that COVID-19 is more active in temperate climates with low temperatures, which explains the reason for the high contagion and deaths in these regions of the world, since it is almost inert to temperatures above $28^{\circ} \mathrm{C}$. However, it reproduces satisfactorily in relative humidities above $60 \%$, which are easy to find in tropical countries. Consequently, temperature and humidity are the two variables of greatest importance for virus survival.

Scientists from the University of Turin in Italy, whose country is one of the most affected by the pandemic, discovered that the virus wreaks greater havoc in patients with Vitamin D deficiency, which is very common in people in European countries, product of winter, which affects the time of exposure to the sun, causing a deficiency of this vitamin, being very important for lung tissue, weakening more rapidly when infected with COVID-19.

For this reason, this virus, as well as other causes of respiratory pathologies, are highly contagious and dangerous for humans when there is a deficiency of vitamins D, C and B vitamins, as well as: folic acid, zinc and magnesium, essential for a vigorous immune system and whose incubation period (period of time in which the symptoms appear, after the person acquired the virus in their body) can be up to less than 6 hours, like the viruses of the "Corona" family [5].

Coronaviruses are those viruses that cause the flu and/or influenza and there are several well-known serotypes, due to the pandemics they have caused, such as: SARS, MERS and now COVID-19, which is wreaking havoc not only for deaths caused, but also, to the detriment of the world economy $[5,6]$.

This virus is highly pathogenic and is transmitted through body fluids, such as saliva, mucus, and tears. COVID-19 was medically detected in the city of Wuhan in the People's Republic of China late last year. It started like any flu, but then they realized that it was more than just a virosis, since deaths increased exponentially in relation to the contagion curves, spreading almost everywhere in the world, affecting more than 130 countries.

COVID-19 has a large molecular size and its recognition proteins are found in the human respiratory tract (oropharynx, bonchia, bronchioles, alveoli and lung tissue), therefore, its symptoms are similar to those of any flu: dry cough, fevers of $38^{\circ} \mathrm{C}$ or more, general discomfort and dyspnea (shortness of breath), the latter being an indispensable symptom for considering a possible contagion by this virus, which in the worst case causes pneumonia, complicating the clinical picture of the infected patient [6].

After exposure to the virus, there is an average of 14 days of incubation, the first 4 or 5 days, COVID-19 lodges in the throat causing the first symptoms of a common flu. These days are crucial for the body, since it does not have specific antibodies against the virus, for this reason, having a well-strengthened immune system is important to combat the symptoms and gradually recover until achieving a full recovery [7].

Autopsy studies conducted in China on people killed by the coronavirus show that the virus affects the mucus-secreting glands of the lower respiratory tract, producing mucus that blocks the air passageways to the lungs from the oropharynx, This explains the difficulty of breathing in patients with COVID-19, since the mucus 
is more viscous than that of a common flu, since the glandular tissue is severely affected. Furthermore, this mucus can be used by the virus as a defense mechanism, just like intestinal unicellular parasites that cause dysentery [8].

After the first week of onset of symptoms, the virus descends into the bronchi and lung tissue, causing in most cases bilateral pneumonia that depresses lung tissue, rendering it insufficient for normal lung function, causing an arrest. cardio-respiratory and leading the infected patient to death [7].

In this sense, it is important to take into account preventive hygiene measures for COVID-19. Among them we can mention: hand washing every 3 hours, when coughing or sneezing, place the forearm to cover the mouth and avoid spreading micro-drops of saliva and mucus in the air as much as possible, using alcohol on the hands if it has touched handrails or if you have used public transport, use face masks if you are leaving the house to make essential purchases and/or medications. However, the best recommendation given by the World Health Organization is "DO NOT LEAVE HOME UNNECESSARILY" to avoid the risk of contagion.

There is no specific treatment for the virus, only the symptoms are controlled until the body begins to recover gradually. However, Cuba has used a medicine called Interferon Alfa 2B, which has given good results in recovered patients. In Colombia and other countries, they are using Chloroquine, to combat this disease, which is a medicine used for Malaria and other pathologies, but which is useful to combat crisis episodes in patients infected with COVID-19.

\section{Conclusion}

COVID-19 is a highly dangerous virus if the symptoms prior to pneumonia are not treated in time. Therefore, it is essential to have a strengthened immune system so that the disease does not pass into critical episodes. Many patients even recover little by little at home, without needing to be hospitalized. It is important to follow the recommendations by local, regional, national and international organizations on hygienic care at home and at the community level to avoid the risk of contagion by this new virus.

\section{References}

[1] Palella S. y Martins, F. (2012). Metodología de la investigación cuantitativa (5 ed.). Fondo Editorial de la Universidad Pedagógica Experimental Libertador. Caracas. Venezuela. 258 pp.

[2] Hurley, W. and Theil, P. (2011). Perspectives on inmunoglobulins in colostrum and milk. Nutrients; 3(4): $442-474$.

[3] Huang C, Wang Y, Li X, Ren L, Zhao J, Hu Y, Zhang L, Fan G, Xu J, and Gu X. (2020). Clinical features of patients infected with 2019 novel coronavirus in Wuhan, China. Lancet; 395:P497-506.

[4] Lorite, N. (2020). Comprendiendo la amenaza global del Coronavirus Covid-19. Madrid. Biloba.

[5] Li Q, Guan X, and Wu P. (2020). Early Transmission dynamics in Wuhan, China, of novel coronavirus-infected pneumonia. N Engl J Med, [Epub ahead of print]. DOI: 10.1056/NEJMoa2001316.

[6] Wang C, Horby PW, Hadyen FG, and Gao GF. (2020). A novel coronavirus outbreak of global health concern. Lancet; 395:P470-3.

[7] Zhu N, Zhang D, Wang W, Li X, Yang B, Song J, Zhao X, Huang B, Shi W, Lu R, Niu P, Zhan F, Ma X, Wang D, Xu W, Wu G, Gao GF, and Tan W. (2020). A novel coronavirus from patients with pneumonia in China, 2019. N Engl J Med; 382:727-33.

[8] Guan WJ, Ni ZY, Hu Y, Liang WH, Ou CQ, He JX, Liu L, Shan H, Lei CL, Hui DSC, Du B, Li LJ, Zeng G, Yuen KY, Chen RC, Tang CL, Wang T, Chen PY, Xiang J, Li SY, Wang JL, Liang ZJ, Peng YX, Wei L, Liu Y, Hu YH, Peng P, Wang JM, Liu JY, Chen Z, Li G, Zheng ZJ, Qiu SQ, Luo J, Ye CJ, Zhu SY, and Zhong NS. (2020). China Medical Treatment Expert Group for Covid-19: Clinical characteristics of coronavirus disease 2019 in China. N Engl J Med. [Epub ahead of print]. DOI: 10.1056/NEJMoa2002032. 